\title{
Hemodynamic assessment during exercise after left ventricular aneurysmectomy
}

The exercise hemodynamics of eight patients who underwent cardiac catheterization were assessed at rest and during exercise, before and after left ventricular aneurysmectomy by the classical technique. Left ventricular end-diastolic volume increased before operation and then significantly decreased after the operation $(p<0.05)$. The ejection fraction increased from 0.27 before the operation to 0.46 after the operation $(p<0.01)$. The cardiac index, which was low before operation, increased within the normal range after operation. Mean systolic circumferential tension also decreased significantly $(p<0.01)$ after the operation. Thus, the indexes at rest showed improvement. Left ventricular enddiastolic pressure showed a decreasing tendency after the operation both at rest and during exercise in comparison with that before the operation. However, the difference was not significant. The stroke work index increased significantly during exercise after the operation $(p<0.05)$. Before the operation, the stroke work index did not increase despite the elevation of left ventricular end-diastolic pressure; however, after the operation, the stroke work index increased during exercise without much increase of left ventricular end-diastolic pressure. This indicated improvement in the Frank-Starling curve and recovery of preload reserve by the resection of the left ventricular aneurysm. Thus, an important factor for demonstrating improvement in postoperative cardiac function was clarified through its relation to exercise load. (J ThORAC CaRdiovasC Surg 1994;107:178-83)

Kanji Kawachi, MD, Soichiro Kitamura, MD, Tetsuji Kawata, MD, Ryuichi Morita, MD, Tsutomu Nishii, MD, Toshio Seki, MD, Shigeki Taniguchi, MD, and Kiyoshi Inoue, MD, Nara, Japan

E ven today, the effects of left ventricular (LV) aneurysmectomy in patients with myocardial infarction are being discussed. Among these effects, the improvement of cardiac function in patients with congestive heart failure is the most important. There have been many reports ${ }^{1-4}$ on the clinical and hemodynamic effects of aneurysmectomy on the patient at rest. However, few have reported on the hemodynamic changes during exercise. It was reported that the postoperative hemodynamic response during exercise could be improved ${ }^{5}$ or that it hardly changed. ${ }^{6,7}$ Thus, the hemodynamic effect of aneurysmectomy during exercise has not been clarified.

From the Department of Surgery III, Nara Medical College, Nara, Japan.

Received for publication Feb. 22, 1993.

Accepted for publication May 24, 1993.

Address for reprints: Kanji Kawachi, MD, Department of Surgery III, Nara Medical College, 840 Shijo-cho, Kashihara, Nara, Japan 634.

Copyright $\odot 1994$ by Mosby-Year Book, Inc.

$0022-5223 / 94 \$ 1.00+.10 \quad 12 / 1 / 49612$
In the present study, we attempted to clarify the effects of the aneurysmectomy on LV function by assessing hemodynamic response at rest and during exercise before and after the operation.

\section{Patients and methods}

Eight male patients underwent $\mathrm{LV}$ aneurysmectomy. The mean age at the time of operation was $50 \pm 10$ years (Table I). In all cases, the electrocardiogram revealed extensive infarction from the anterior to the lateral wall. Four patients had symptoms of congestive heart failure and angina pectoris, one had angina pectoris and ventricular tachyarrhythmia, and three had congestive heart failure alone. The mean New York Heart Association functional class was $3.1 \pm 0.4$ before the operation. Operations were generally performed with cardiopulmonary bypass with cold cardioplegic solution and topical cooling for myocardial protection. Systemic hypothermia $\left(25^{\circ}\right.$ to $\left.27^{\circ} \mathrm{C}\right)$ was used. Operation in one patient was performed while myocardial blood flow was preserved with the use of hypothermic ventricular fibrillation with continuous pulsatile coronary and systemic blood flow by intraaortic balloon pumping without an aortic crossclamp. A discrete anteroapical aneurysm was confirmed in all patients at operation. In most of the patients, the thinned-out myocardium was incised. A $1 \mathrm{~cm}$ margin of scar 

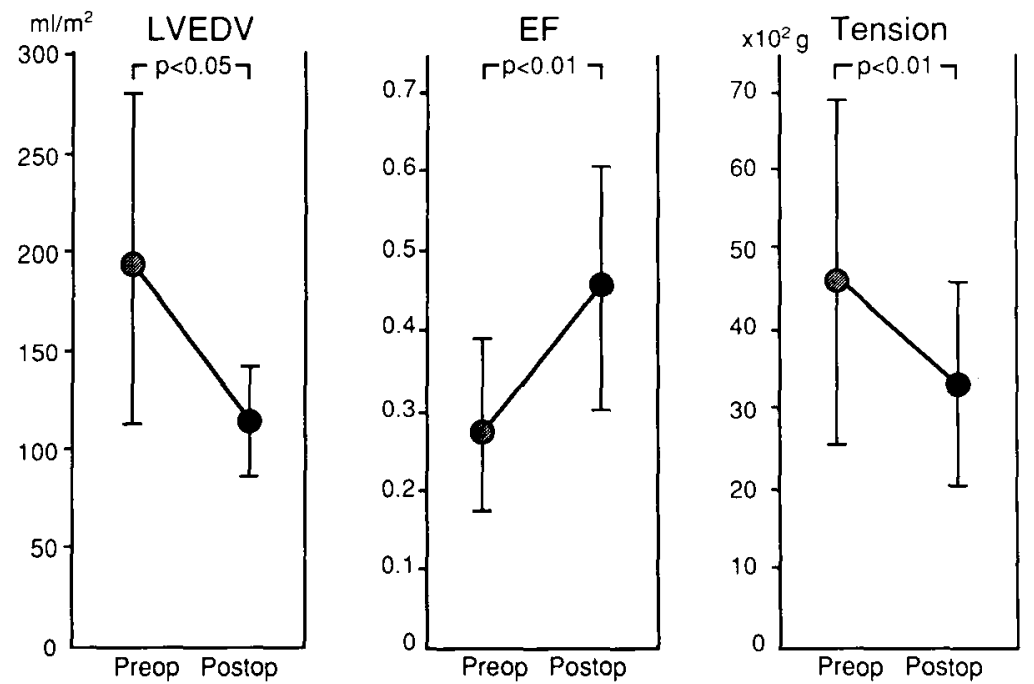

Fig. 1. Plots of hemodynamics at rest before and after the operation. LVEDV and wall tension (Tension) significantly decreased after the operation. EF significantly increased after the operation.

was retained at the perimeter of the excised myocardium. The edges of the myocardium were closed with multiple mattress sutures over Teflon felt bolsters and then oversewn with a single running suture. No patient had an abnormality of the mitral valve apparatus at operation. Three patients underwent concomitant bypass operation to the right coronary artery, and two patients underwent bypass to the diagonal branch. The aneurysm of the LV occupied $32 \%$ to $78 \%$ of the total end-diastolic volume. The extent of the myocardial resection of the infarcted area covered 45 to $97 \mathrm{~cm}^{2}$. Preoperative total LV ejection fraction (EF) was $0.27 \pm 0.13$, and EF of contractile section of the $\mathrm{LV}$ was $0.39 \pm 0.08$

Postoperative hemodynamic measurements were performed at an average of $5.3 \pm 2.4$ months after the operation. Signed consent was obtained before and after the operation. The patency of the graft was ascertained in all cases. Right and left heart catheterizations were carried out with the patient in the supine position, at rest and during exercise before and after the operation. Intracardiac pressures and cardiac output were measured by means of the dye-dilution method. The exercise load was applied by supine leg exercise with a bicycle ergometer at 50 watts for 5 minutes. The $\mathrm{LV}$ volume was calculated by the area-length method. ${ }^{8}$ The size of the LV aneurysm was calculated by the method of Watson, Dickhaus, and Martin. ${ }^{9}$ The percentage of area of the aneurysm was calculated by the enddiastolic volume of noncontractile section/total LV end-diastolic volume $($ LVEDV) $\times 100$. Tension during the LV ejection period was calculated as mean systolic circumferential tension with the use of a thin wall spherical model. ${ }^{10}$ The results were expressed as the mean \pm standard deviation. The data at rest were analyzed with Student's $t$ test. Statistical assessment of exercise hemodynamics was carried out with analysis of variance. Scheffe's methods were used to specify differences when analysis of variance indicated a significant difference.

\section{Results}

Symptomatic improvement in all patients was shown after the operation. The mean New York Heart Associ-
Table I. Patient characteristics in eight patients with left ventricular aneurysmectomy

\begin{tabular}{lc}
\hline Age $(\mathrm{yr})$ & $50 \pm 10$ \\
Sex $(\mathrm{M} / \mathrm{F})$ & $8: 0$ \\
LV aneurysmectomy (No. of & 3 \\
$\quad$ patients) & 5 (RCA 3, Dx 2) \\
LV aneurysmectomy + CABG & \\
$\quad$ (No. of patients) & \\
Location of aneurysm (No. of patients) & 8 \\
$\quad$ Anterolateral & $3.1 \pm 0.4$ \\
NYHA & $0.27 \pm 0.13$ \\
Total ejection fraction & $0.39 \pm 0.08$ \\
\hline
\end{tabular}

Values are given as mean \pm standard deviation. $C A B G$, Coronary artery bypass grafting; $R C A$, right coronary artery; $D x$, diagonal branch; $N Y H A$, New York Heart Association functional class; CSEF, EF of contractile section of LV.

ation functional class was $3.1 \pm 0.4$ before the operation and decreased to $1.3 \pm 0.5$ after the operation $(p<0.01)$.

Hemodynamics at rest. The preoperative LVEDV increased to an average of $193 \pm 99 \mathrm{ml} / \mathrm{m}^{2}$. However, the LVEDV decreased to $115 \pm 30 \mathrm{ml} / \mathrm{m}^{2}$ after the operation $(p<0.05)$. EF was as low as $0.27 \pm 0.13$ before the operation, and increased to $0.46 \pm 0.16$ after the operation $(p<0.01)$. The wall tension was reduced from a preoperative value of $4700 \pm 2200 \mathrm{~g}$ to a postoperative value of $3300 \pm 1300 \mathrm{~g}(p<0.01$; Fig. 1$)$.

Hemodynamics during exercise. The heart rate at rest was $72 \pm 13$ beats $/ \mathrm{min}$ before the operation and $74 \pm 9$ beats $/ \mathrm{min}$ after the operation, showing no significant difference. The heart rate during exercise was $98 \pm 11$ beats $/ \mathrm{min}$ and $105 \pm 12$ beats $/ \mathrm{min}$, respectively, showing no significant difference. At both times, the 

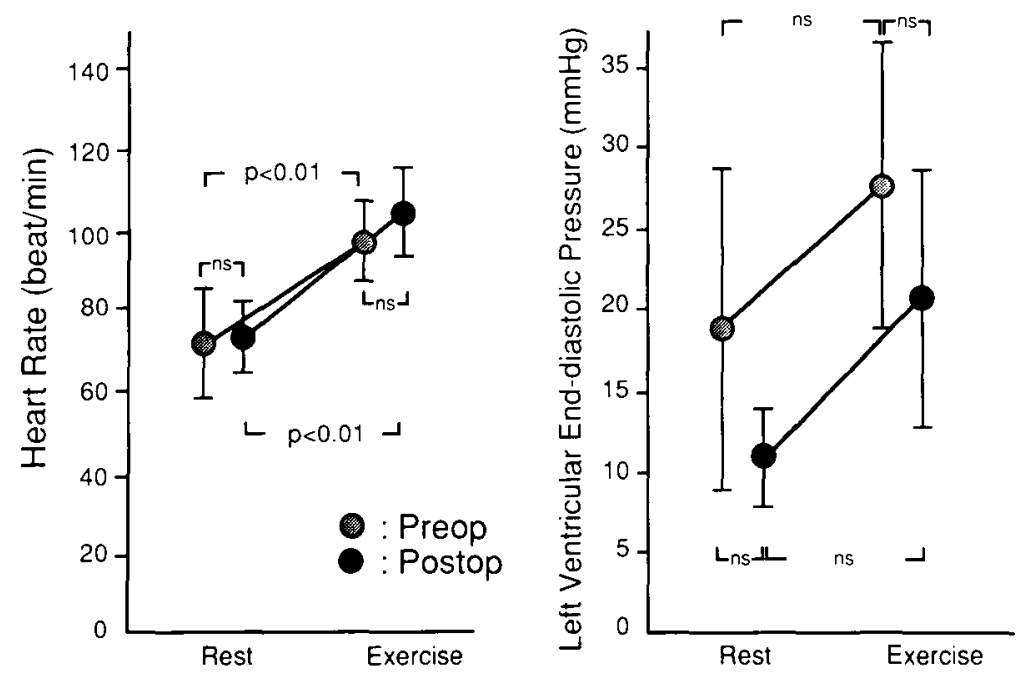

Fig. 2. Plots of heart rate and LVEDV at rest and during exercise before and after the operation. Heart rate before and after the operation increased during exercise $(p<0.01)$. The abnormally high preoperative LVEDP decreased after the operation, but the difference was not significant. LVEDP during exercise slightly increased both before and after the operation.
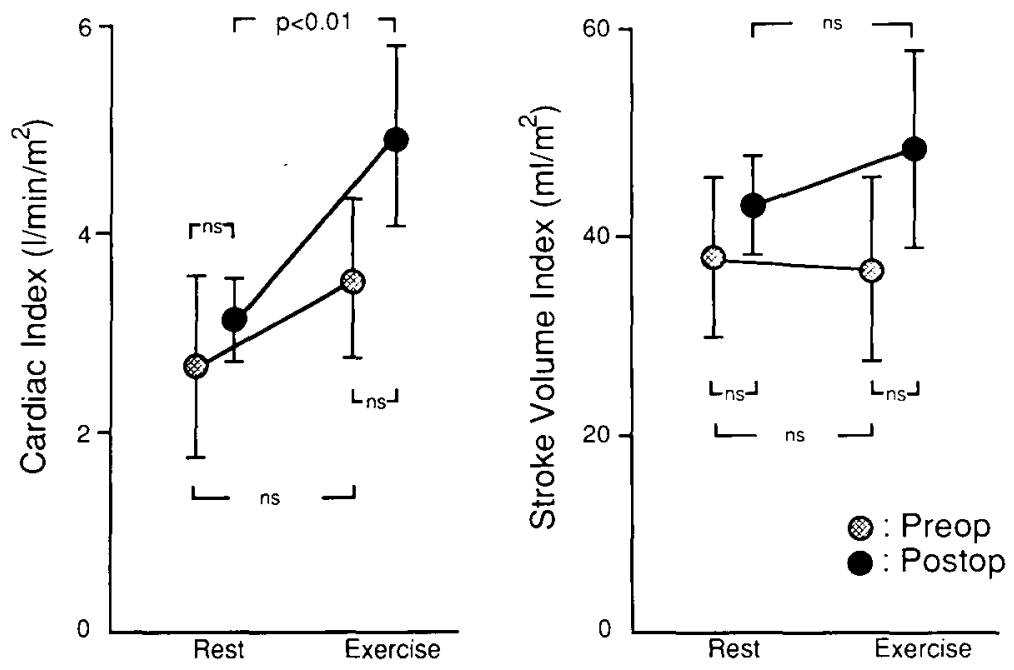

Fig. 3. Plots of cardiac index and SVI at rest and during exercise before and after the operation. Cardiac index during exercise increased significantly after the operation $(p<0.01)$. SVI before the operation showed no significant change during exercise. SVI increased during exercise after the operation. However, the difference was not significant.

heart rate during exercise was significantly higher than the rate at rest, increasing by $42 \%(p<0.01)$ and $44 \%$ $(p<0.01$ ), respectively (Fig. 2). The LV end-diastolic pressure (LVEDP) before and after the operation at rest were $19 \pm 10 \mathrm{~mm} \mathrm{Hg}$ and $11 \pm 3 \mathrm{~mm} \mathrm{Hg}$, respectively (Fig. 2). The abnormally high preoperative value decreased after the operation, but the difference was not significant. During exercise, the LVEDP before and after the operation was $29 \pm 10 \mathrm{~mm} \mathrm{Hg}$ and $21 \pm 9 \mathrm{~mm} \mathrm{Hg}$, respectively. Although the values were high, no significant difference was observed.

Cardiac index at rest was as low as $2.63 \pm 0.9 \mathrm{~L} / \mathrm{min}$ per square meter before the operation but increased slightly to $3.10 \pm 0.47 \mathrm{~L} / \mathrm{min}$ per square meter after the operation with no significant difference (Fig. 3). Cardiac index during exercise was $3.53 \pm 0.84 \mathrm{~L} / \mathrm{min}$ per square meter before the operation and $4.93 \pm 1.00 \mathrm{~L} / \mathrm{min}$ per square meter after the operation. Although the postoper- 


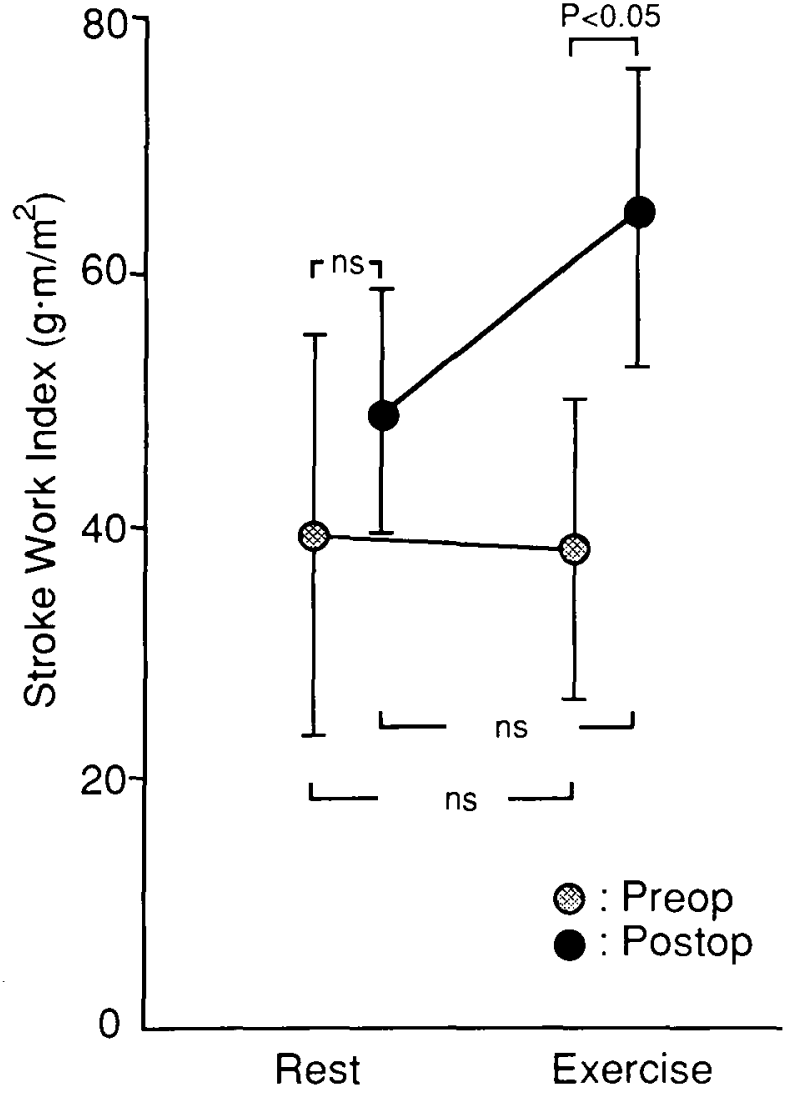

Fig. 4. Plots of SWI at rest and during exercise before and after the operation. SWI at rest slightly increased after the operation but with no significant difference. Postoperative exercise SWI significantly increased compared with preoperative exercise SWI $(p<0.05)$.

ative value was higher than the preoperative value, the difference was insignificant. The cardiac index during exercise increased significantly in comparison with that at rest, after the operation $(p<0.01)$.

Stroke volume index (SVI) at rest was $35 \pm 6 \mathrm{ml} / \mathrm{m}^{2}$ before the operation and $42 \pm 9 \mathrm{ml} / \mathrm{m}^{2}$ after the operation (Fig. 3). During exercise, SVI was $36 \pm 10 \mathrm{ml} / \mathrm{m}^{2}$ before and $48 \pm 10 \mathrm{ml} / \mathrm{m}^{2}$ after the operation. The postoperative values were higher, but with no significant difference.

Stroke work index (SWI) at rest was $39 \pm 17 \mathrm{~g} \cdot \mathrm{m} /$ $\mathrm{m}^{2} /$ beat before the operation and $49 \pm 10 \mathrm{~g} \cdot \mathrm{m} / \mathrm{m}^{2} /$ beat after the operation (Fig 4). During exercise before and after the operation, SWI was $38 \pm 13$ and $65 \pm 13$ $\mathrm{g} \cdot \mathrm{m} / \mathrm{m}^{2} /$ beat, respectively. The postoperative values were significantly higher than the preoperative values during exercise $(p<0.05)$. In comparison with the SWI at rest, the SWI during exercise did not change significantly before and after the operation. Changes in

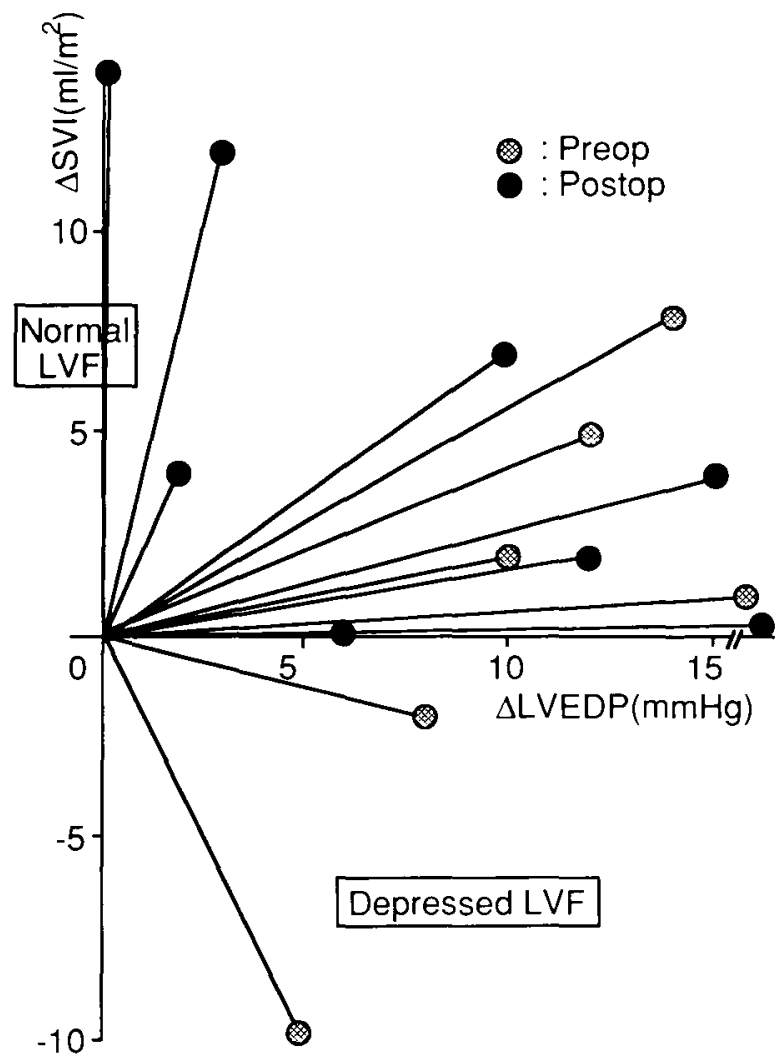

Fig. 5. Plots of relation between $\triangle$ LVEDP and $\Delta$ SVI. In two patients, $\triangle$ LVEDP was increased and $\triangle$ SVI was decreased, which indicated depressed LV function before the operation. After the operation, both $\triangle$ LVEDP and $\triangle$ SVI were increased in all patients. This relation represents normal or abnormal $\mathrm{LV}$.

SVI and LVEDP were shown by plotting the difference between the resting and exercise values for SVI $(\Delta S \mathrm{SVI})$ on the vertical axis and the difference between the resting and exercise values for LVEDP ( $\triangle$ LVEDP) on the horizontal axis in Fig. 5. Before the operation, two of the six patients showed decreased $\triangle$ SVI and increased $\triangle$ LVEDP, classifying their conditions in what Ross and associates ${ }^{11}$ called a depressed LV function group. After the operation, all patients demonstrated increased $\triangle \mathrm{SVI}$ and $\triangle$ LVEDP, indicating improvement. The changes before and after the operation in SWI and LVEDP at rest and during exercise are shown in Fig. 6. SWI was plotted on the vertical axis and LVEDP on the horizontal axis. After the operation, LVEDP at rest and during exercise decreased compared with the preoperative values, whereas SWI showed an increase, the values shifting to the upper left portion of Fig. 6 . This shift indicated improvement in the Frank-Starling curve. 


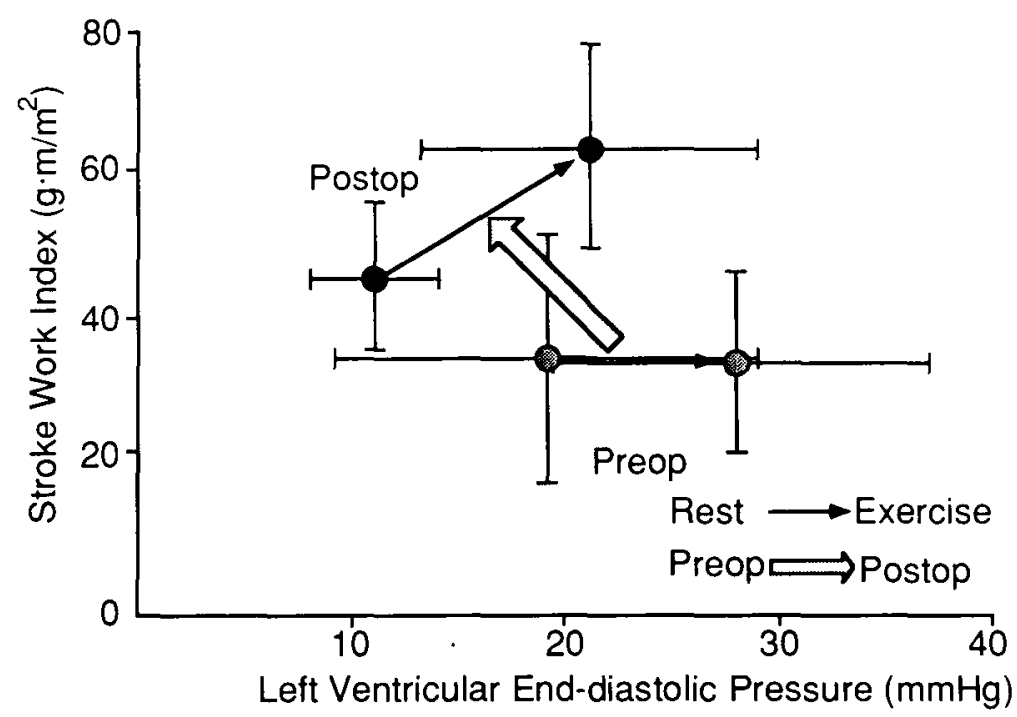

Fig. 6. Plots of the changes of SWI and LVEDP at rest and during exercise before and after the operation. After the operation, LVEDP at rest and during exercise slightly decreased compared with the preoperative value, whereas SWI slightly increased. These values shifted to the upper left portion of this figure.

\section{Discussion}

The important effect of the LV aneurysmectomy was to improve $L V$ function by reducing $L V$ volume and wall tension, lowering LVEDP. ${ }^{1-4}$ The reduction in wall tension is considered to be concomitant with reduction in myocardial oxygen demand ${ }^{2}$ and relieve angina.

Conversely, it has been reported that only limited hemodynamic improvement was observed after LV aneurysmectomy. Stephens and associates ${ }^{6}$ found that after aneurysmectomy, SVI did not change, but LVEDP decreased at rest. In patients with severe symptoms and low EF at the contractile area of the LV, hemodynamic improvement was marked, whereas in patients with mild symptoms, the improvement was slight. In contrast, our results showed increase in cardiac output. After the operation, LVEDP showed a tendency to decrease, but no statistical difference was found.

Kitamura and associates ${ }^{1}$ reported that the aneurysmectomy brought about reduction in LVEDV, increase in $\mathrm{EF}$, and reduction in wall tension and LVEDP. They pointed out the formation of a new Frank-Starling curve of the new LV with significant reduction in LVEDV; that is, there were improvements in preload reserve and afterload mismatch because of reduction in wall tension, as factors in the recovery of LV function as a whole after LV aneurysmectomy.

Concerning reports that the postoperative improvement at rest was small, Froehlich and associates ${ }^{12}$ indicated that postoperative improvement in EF of over $10 \%$ was observed in just a few cases ( 4 of 18) and that LVEDP did not change. Sesto and associates ${ }^{13}$ reported that LV volume decreased, LVEDP did not decrease, and there was no improvement in EF. These results may be due to an insufficient aneurysmectomy, the small size of the aneurysm, or very poor contractile condition of the remaining $L V$. Thus, data only while patients are at rest may be inappropriate for the evaluation of the effect of an aneurysmectomy. Therefore, it is considered important to study cardiac function during exercise to understand the reserve of the contractile section of the LV.

In reference to exercise hemodynamics, Balu and associates ${ }^{5}$ reported that double product increased after the operation in response to exercise load, resulting in an increase in exercise tolerance. However, there have been extremely few reports on the hemodynamic response to the stress of exercise. Stephens and associates ${ }^{6}$ indicated in their measurements at 8 months after the operation that cardiac index and SVI did not show any changes during exercise but that LVEDP decreased in comparison to preoperative values both at rest and during exercise. Their colleagues, Dymond and associates ${ }^{7}$ studied the changes during exercise with the use of LV angiography with radioisotope and reported that the postoperative EF was elevated at rest but showed no change during exercise. They also reported that although the postoperative LVEDP decreased during exercise, it still showed abnormal values, which was determined to be an abnormal response to exercise.

Although, in the relation between $\triangle$ LVEDP and $\Delta S V I$, two patients had depressed LV function before the 
operation, all patients had no evidence of depressed LV function after the operation. Therefore, the cardiac reserve during exercise was considered to have improved compared with the level before the operation. It has been reported that LVEDP during exercise in a normal control patient is as high as $16 \mathrm{~mm} \mathrm{Hg} .{ }^{14}$ LVEDPs measured after the operation in the present study were still high and far from normal.

SWI and LVEDP values at rest and during exercise before and after the operation shifted to the upper left portion of the graph (Fig. 6). Improvements of preload reserve occurred and thereby a favorable shift of FrankStarling curve of the new LV resulted from LV aneurysmectomy.

\section{REFERENCES}

1. Kitamura S, Echevarria M, Kay JH, et al. Left ventricular performance before and after removal of noncontractile area of the left ventricle and revascularization of the myocardium. Circulation 1972;45:1005-17.

2. Kawachi K, Kitamura S, Kawashima Y, et al. Changes in myocardial oxygen consumption and coronary sinus blood flow before and after resection of left ventricular aneurysm after myocardial infarction. J THORAC CARDIOVASC SURG 1987;94:566-70.

3. Kiefer SK, Flaker GC, Martin RH, Curtis JJ. Clinical improvement after ventricular aneurysm repair: prediction by angiographic and hemodynamic variables. JACC 1983;2:30-7.

4. Magovern GJ, Sakert T, Simpson K, et al. Surgical therapy for left ventricular aneurysms. Circulation 1989;79 (Suppl):I102-7.

5. Balu V, Hook N, Dean DC, Naughton J. Effect of left ven- tricular aneurysmectomy on exercise performance. Intern J Cardiol 1984;5:210-3.

6. Stephens JD, Dymond DS, Stone DL, Rees GM, Spurrell RAJ. Left ventricular aneurysm and congestive heart failure: Value of exercise stress and isosorbide dinitrate in predicting hemodynamic results of aneurysmectomy. Am $\mathbf{J}$ Cardiol 1980;45:932-9.

7. Dymond DS, Stephens JD, Stone DL, Elliott AT, Rees GM, Spurrell RAJ. Combined exercise radionuclide and hemodynamic evaluation of left ventricular aneurysmectomy. Am Heart J 1982;104:977-87.

8. Kitamura S, Kawashima Y, Horiguchi Y, et al. Analysis of factors that affect the accuracy of volume measurement by angiocardiography. Shinzo 1973;5:1224-34.

9. Watson LE, Dickhaus DW, Martin RH. Left ventricular aneurysm: preoperative hemodynamics, chamber volume, and results of aneurysmectomy. Circulation 1975;52:86873.

10. Paley HW, McDonald IG, Blumenthal J, Mailhot J, Modin GW. The effects of posture and isoproterenol on the velocity of left ventricular contraction in man. J Clin Invest 1971;50:2283-94.

11. Ross J Jr, Gault JH, Mason DT, Linhart JW, Braunwald E. Left ventricular performance during muscular exercise in patients with and without cardiac dysfunction. Circulation 1966;34:597-608.

12. Froehlich RT, Falsetti HL, Doty DB, Marcus ML. Prospective study of surgery for left ventricular aneurysm. Am J Cardiol.1980;45:923-31.

13. Sesto M, Schwartz F, Thiedemann KU, Flameng W, Schlepper M. Failure of aneurysmectomy to improve left ventricular function. Br Heart J 1979;41:79-88.

14. Thadani U, Parker JO. Hemodynamic at rest and during supine and sitting bicycle exercise in normal subjects. Am J Cardiol 1978;41:52-9. 